\title{
Fields of Applications and Transport-Related Potentials of Small Electric Vehicles in Germany
}

\author{
Christine Eisenmann, Johannes Gruber, Mascha Brost, \\ Amelie Ewert, Sylvia Stieler, and Katja Gicklhorn
}

\begin{abstract}
The possible applications of small electric vehicles, i.e., electric cargo bikes and three- and four-wheeled L-class vehicles in transport, are discussed, and potential business models are presented. Moreover, transport-related potentials are analyzed. Therefore, we have utilized a multi-method approach: we conducted qualitative interviews with experts and professionals in the field of light and small electric vehicles and carried out quantitative analyses with the national household travel survey mobility in Germany 2017. Our results show that, theoretically, small electric vehicles could be used for $20-50 \%$ of private trips (depending on the model). On these trips, however, they would not only replace car trips, but also trips on public transport or by bicycle and on foot. In commercial transport, these vehicles are particularly suitable for service trips and some last-mile deliveries. If small electric vehicles were to replace a significant share of the transport volumes of motorized passenger and commercial transport, they could contribute to climate protection.
\end{abstract}

Keywords Small electric vehicles - Mobility in Germany MiD • Transport impacts $\cdot$ User potentials $\cdot$ LEV applications

C. Eisenmann $(\bowtie) \cdot$ J. Gruber

German Aerospace Center (DLR), Institute of Transport Research,

Rudower Chaussee 7, 12489 Berlin, Germany

e-mail: Christine.Eisenmann@dlr.de

M. Brost · A. Ewert

German Aerospace Center (DLR), Institute of Vehicle Concepts, Wankelstaße 5,

70563 Stuttgart, Germany

S. Stieler

IMU Institut, Hasenbergstraße 49, 70176 Stuttgart, Germany

K. Gicklhorn

e-Mobil BW GmbH, Leuschnerstraße 45, 70176 Stuttgart, Germany

(C) The Author(s) 2021

A. Ewert et al. (eds.), Small Electric Vehicles,

https://doi.org/10.1007/978-3-030-65843-4_10 


\section{Introduction}

Climate change, congestion, air pollution, and increasing transport volumes are putting pressure on cities and municipalities worldwide to enhance sustainable transport and mobility. Politicians, decision makers, and transport researchers are aiming to reduce land use, satisfy people's desire for mobility and goods availability, and improve air quality and the quality of life in cities. Small and light electric vehicles (SEVs) are seen as a feasible factor in meeting these challenges [13]. The global market is developing dynamically in regard to SEV sales, particularly in Asian countries like China and India [4]. In Europe, however, sales are very low, and SEVs are not widely available [5]. Moreover, at present, the framework conditions in Germany might hinder a broader market adoption of SEVs [6]. Applying supporting measures could foster a more widespread use. Therefore, it is important to analyze the possible potential of SEVs in respect to their impact on transport. Against this background, our contribution addresses the following three topics:

1. Transport impacts: What is the share of transport demand in passenger transport and commercial transport that could be substituted by SEVs? On which trips could SEVs be used?

2. User potentials: For which user groups are SEVs suitable in terms of socio-demographic characteristics?

3. Applications and business models: What are the possible applications of SEVs in passenger transport and commercial transport? Which business models might be conceivable and suitable for SEVs?

SEV Definition The presented analyses focus on three-wheeled (L2e and L5e) and four-wheeled (L6e and L7e) SEVs according to EU regulation No. 168/2013 as well as electric cargo bikes. Cargo bikes can be two-, three- or four-wheeled with and without insurance tags.

\section{Materials and Methods}

We utilized a multi-method approach to answer our research questions: we conducted qualitative expert interviews amongst SEV experts and professionals and carried out quantitative analyses with national household travel survey (NHTS) data. We have furthermore compared and contrasted our results with scientific literature. For the present publication, the NHTS data analysis is focused on Germany. The expert interviews, in contrast, refer to the German Federal State Baden-Württemberg appropriate to the primary study. 


\subsection{Qualitative Expert Interviews}

SEVs are rarely used in Germany. Hence, statistics on the, e.g., employment effects and economic impacts of SEVs in Germany do not exist yet. In order to broaden our findings from literature and travel survey analyses, we have conducted eleven expert interviews. We developed an interview guideline, which we have used as a basis for each interview. For a comprehensive view, the interviewed experts cover a wide range of expertise: from entrepreneurs of small, medium-sized, and global corporations to scientists and representatives of the state government of Baden-Württemberg. This included expertise in the production and sale of SEVs as well as the assessment of the legal framework in the study. The interviews were recorded and analyzed for congruence. Our conclusions are based on according statements. The content-related statements from the experts helped to evaluate the quantitative findings from data analysis and to formulate recommendations for action. In accordance with the sponsor (e-mobil BW $\mathrm{GmbH}$ ) of the study, the interviews serve for a first exploration of the research field.

\subsection{Quantitative Data Analyses with the NHTS Mobility in Germany}

The NHTS Mobility in Germany (MiD) The MiD is a nationwide, comprehensive survey on travel behavior and transport demand of the German residential population [7]. The current survey was conducted in 2017; former surveys date back to 2002 and 2008 .

The MiD is a one-day survey, i.e., each participant reported their mobility on a given day, i.e., the survey day. The field phase of the MiD 2017 took place between May 2016 and September 2017. Therefore, a mixed-mode approach was applied: the participants took part in the survey either by paper and pencil questionnaire or by web questionnaire. A total of around 316,000 individuals from 156,000 households participated and reported 961,000 trips on their respective survey days.

The MiD 2017 survey offers various levels of data analysis. The central component is the trip data set, which contains all trips made by the survey participants on their survey days. This data set contains, for example, trip-specific information on departure and arrival time, purpose, modes of transport, distance travelled, and accompaniment by other persons.

If the survey participants make regular trips due to their profession (e.g., mail carrier, craftsmen, bus drivers, elderly care services), information on these trips was collected at a lower level of detail (e.g., only the total distance travelled of all business-related trips on the survey day).

It should be noted that no conclusions can be drawn from the one-day survey data of the MiD 2017 on the travel behavior of individuals and SEV user potential 
over longer periods of time. Consequently, no conclusions can be drawn from the MiD information about SEV user potentials of single individuals from a longitudinal perspective. However, the analyses allow to quantify the share of the reported trip chains for which SEVs are suitable according to a defined set of requirements and trip chain specifications. A trip chain is a sequence of trips that start at one place (often at home) and end there again. Thereby, a technical potential of using SEVs can be shown.

Estimation of the Maximum Feasible Transport and User Potentials of SEVs For our analysis, we have selected seven characteristic SEV models with heterogeneous vehicle characteristics (e.g., electric range, maximum speed). Those vehicle characteristics were used to determine the characteristics of trip chains on which SEVs can be used. If a trip chain meets all requirements, it is assumed that an SEV can theoretically be used on that trip chain. Tables 1 and 2 provide a summary of the considered SEV models.

With our approach, we are able to determine the maximum feasible potential of SEVs. However, we need to note that the maximum potential shown will never be fully realized. This is because even if there is a large supply of SEVs, not every person will use their SEVs for every trip that they could have taken an SEV on. Other aspects, such as personal preferences or willingness-to-buy, as well as economic feasibility, also impact individual mode choices. For example, many transport users with short commutes could cycle to work, but do not do so because of personal preferences. These aspects were not addressed in the MiD 2017 and can therefore not be included in our analysis.

Vehicles used for commercial transport (e.g., service trips of craftsmen or some types of deliveries) are often provided by the employer. Therefore, SEVs for private use (passenger transport) and SEVs for commercial transport are considered in separate analyses. The data basis for the analysis of private trips is the travel diary of the MiD. The data basis for the analysis in commercial transport is the less detailed dataset of "regular business-related trips" (rbW) of the MiD; therefore, rbW are used as a proxy for commercial transport within this publication.

The results for passenger transport and commercial transport are comparable as the estimations are based on the same survey and method. This was seen as more fruitful than to use the slightly outdated KiD 2010 survey (Motor Vehicle Traffic in Germany 2010), which has been frequently used for empirically-based researched in commercial transport.

In order to determine trip chains for which SEVs could be used, various aspects are examined in a differentiated procedure for each individual trip chain in the MiD. Only if all aspects are applicable, it is assumed that an SEV could be used on this trip chain. We have considered the following aspects:

- Is the electrical range of the SEV sufficient for the distance covered?

- If the person is accompanied by others: Does the SEV offer additional seats?

- If goods need to be transported: Does the SEV have facilities that allow the transport of such objects? 
Table 1 Vehicle and usage characteristics of various SEV models, suited primarily for passenger transport

\begin{tabular}{l|l|l|l|l}
\hline & EVT trike & $\begin{array}{l}\text { Riese \& } \\
\text { Müller } \\
\text { Packster } 80 \\
\text { HS }\end{array}$ & $\begin{array}{l}\text { Aixam eCity } \\
\text { Pack }\end{array}$ & $\begin{array}{l}\text { Micromobility } \\
\text { systems } \\
\text { Microlino }\end{array}$ \\
\hline Range $(\mathrm{km})^{1}$ & 70 & 63 & 75 & 2 \\
\hline Seats & 2 & 1 & 2 & 140 \\
\hline Number of wheels & 3 & 2 & 4 & 2 \\
\hline Goods volume $(\mathrm{l})$ & $\begin{array}{l}\text { Approx. } \\
10\end{array}$ & 135 & 700 & 300 \\
\hline $\begin{array}{l}\text { Maximum speed } \\
\text { (km/h) }\end{array}$ & 45 & 45 & 45 & 90 \\
\hline $\begin{array}{l}\text { Driving license } \\
\text { required }\end{array}$ & Yes & Yes & Yes & Yes \\
\hline Weather protection & No & No & Yes & Yes \\
\hline
\end{tabular}

${ }^{1}$ Practical range estimated on the basis of information provided by manufacturers

Table 2 Vehicle and usage characteristics of various SEV models, suited primarily for commercial transport

\begin{tabular}{|c|c|c|c|c|}
\hline & $\begin{array}{l}\text { Riese \& Müller } \\
\text { Packster } 80 \text { HS }\end{array}$ & $\begin{array}{l}\text { Kyburz } \\
\text { DXP } 4\end{array}$ & Radkutsche & Alkè ATX 320E \\
\hline Range $(\mathrm{km})^{1}$ & 63 & 50 & 68 & 52 \\
\hline Seats & 1 & 1 & 1 & 2 \\
\hline $\begin{array}{l}\text { Number of } \\
\text { wheels }\end{array}$ & 2 & 3 & 3 & 4 \\
\hline $\begin{array}{l}\text { Goods volume } \\
\text { (1) }\end{array}$ & 135 & Variable & Variable & Variable \\
\hline $\begin{array}{l}\text { Maximum } \\
\text { speed }(\mathrm{km} / \mathrm{h})\end{array}$ & 45 & 45 & 25 & 44 \\
\hline $\begin{array}{l}\text { Driving license } \\
\text { required }\end{array}$ & Yes & Yes & No & Yes \\
\hline $\begin{array}{l}\text { Weather } \\
\text { protection }\end{array}$ & No & No & No & Yes \\
\hline
\end{tabular}

${ }^{1}$ Practical range estimated on the basis of information provided by manufacturers 
- Is the permissible maximum speed of the SEV coherent with the road infrastructure that was used on the trip chain?(Estimation based on the average speed on the longest trip of the trip chain)

- If a driving license is required for the SEV: Does the survey participant have the appropriate driving license?

- Does the SEV have sufficient weather protection to enable its use even in unfavorable weather conditions?

A separate analysis is carried out for each of the seven SEV models in Tables 1 and 2. Since the data collection of regular business-related trips is less detailed, only the first two questions can be examined for analysis in commercial transport. We have also taken into account that trip chains should be at least $800 \mathrm{~m}$ long, as shorter trip chains do not justify the time required of access and egress of SEVs.

\section{Results}

The multi-method approach with qualitative expert interviews, quantitative analyses of national household travel survey (NHTS) data, and analysis of scientific literature provides findings on application of SEVs, technical potential of trip or, respectively, transport share which is described in the following sections. Thereafter, we present applications and business models for SEVs. The underlying study of this book chapter evaluates a variety of additional SEV topics including measures that could be implemented for fostering SEVs [8].

\subsection{Feasible Transport Impacts and User Potentials of SEVS in Passenger Transport}

Depending on the respective SEV model, a maximum of $17 \%$ to $49 \%$ of all private trips and 6 to $30 \%$ of the distance covered by private trips can be substituted by SEVs, see Fig. 1. ${ }^{1}$ The electric range and maximum speed in particular limit the substitution potential here.

SEVs with higher ranges and speeds are a feasible alternative, especially on commuting trips and shopping trips: the Microlino could be used on 57\% of all commuting trips and on 59\% of all shopping trips. Figure 2 shows for which share of trips SEVs could be used, which have so far been covered on foot, by bicycle, motorized private transport (MIV), or public transport. Thus, SEVs represent a certain rivalry to environmentally friendly transport modes. Vehicle models with

\footnotetext{
${ }^{1}$ We would like to point out that individual trips in a trip chain could also have been carried out with an SEV (e.g., when using SEV sharing services or when recharging the SEV during the trip chains), but this was not analyzed here.
} 


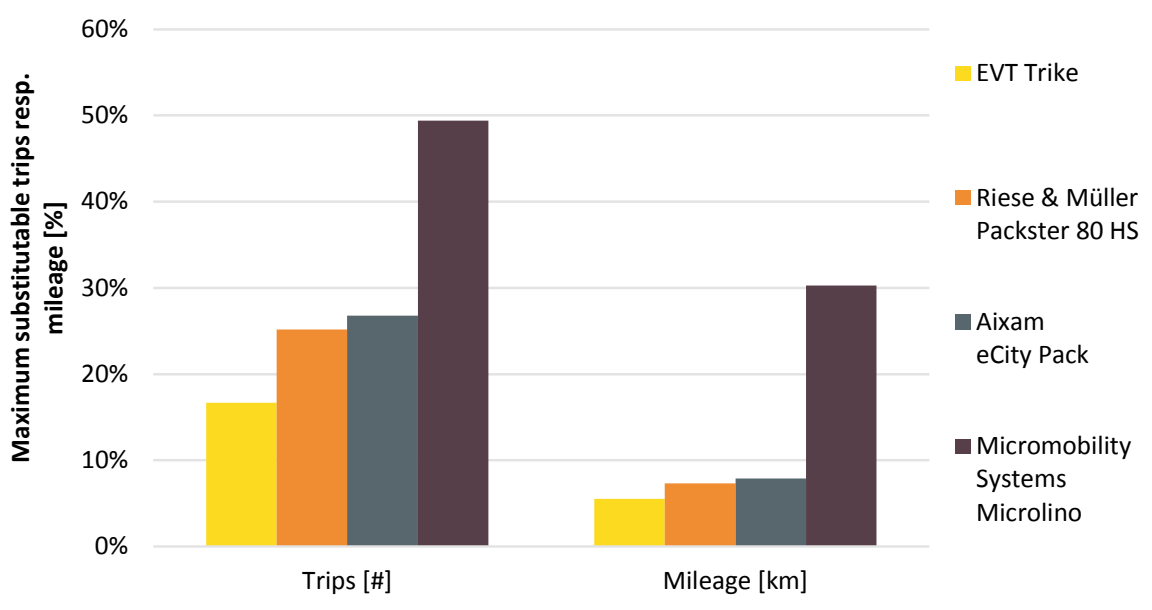

Fig. 1 Share of private trips and mileages on private trips that can be substituted by SEVs (maximum potential)

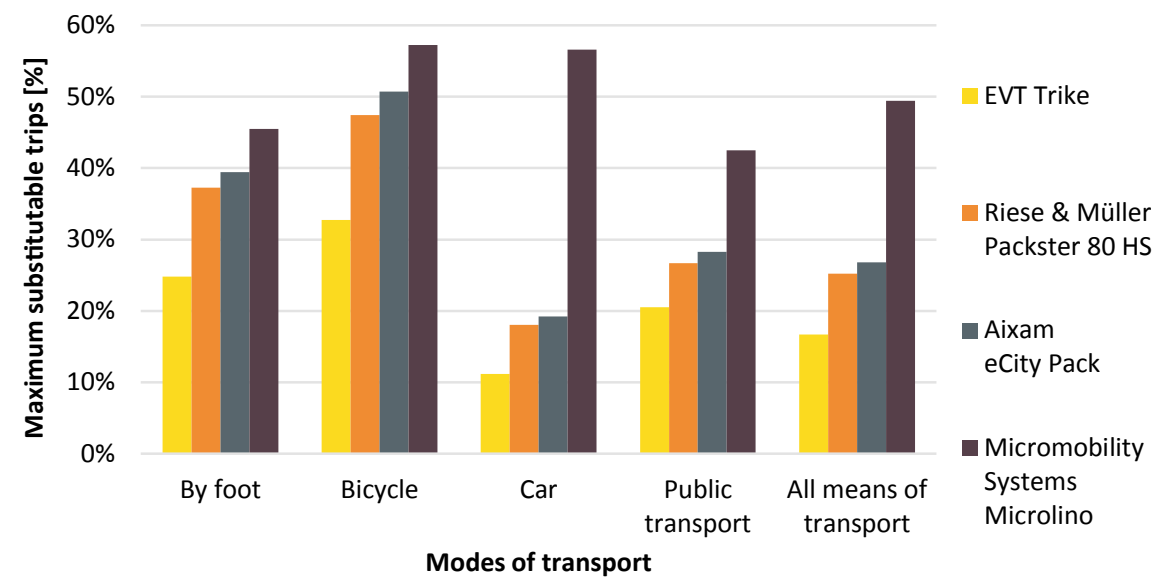

Fig. 2 Proportion of private trips that could be substituted by SEVs, differentiated by previous modes of transport (maximum potential)

lower ranges and maximum speeds are technically suitable for a higher share of trips covered by active modes than trips covered by car. For example, the EVT Trike could be used for a quarter of all trips on foot and a third of all trips by bicycle. In contrast, the EVT Trike could only replace $11 \%$ of car trips and one fifth of all trips by public transport. However, these numbers do not indicate that there is a high risk of replacing environmentally friendly modes of transport as the survey data does not contain information on user willingness to change transport modes. SEV models with larger electric ranges and maximum speeds, such as the Microlino 
on the other hand, are better suited to replace MIV trips instead: After all, 57\% of MIV trips and $42 \%$ of public transport trips could also be made with the Microlino. Regarding active modes of transport, the Microlino is technically suitable for $46 \%$ of walking and $57 \%$ of cycling trips. A major reason why SEVs cannot be used on more walking or cycling trips is that some of the SEVs considered require a driving license. Not all persons who travelled on foot or by bicycle on the survey day have the appropriate driving license. Although trips with active modes are usually within the electric range of SEVs, no higher degree of substitutability is feasible because either a driving license is often required to use the SEV or trip chains on foot are shorter than $800 \mathrm{~m}$.

Moreover, the question arises as to which groups of people could use SEVs in their everyday travel and how large the potential user group is. For this purpose, the MiD 2017 was used to analyze which share of the population on the survey day made trips for which an SEV could also be used, and how these population groups are characterized.

Between 16 and 38\% of the participants in the MiD 2017 survey could have used an SEV on the survey day. These numbers again represent the technical usage maximum without taking personal preferences into account. It can be seen that SEV models with a higher electric range, and maximum speed have more potential to be used on private trips.

There is user potential for SEVs in all age groups from 18 years onward, with the user potential of the age groups from 30 years and older is higher than that of 18-29 year olds (see Fig. 3). The figure shows only persons aged 18 and over, since the MiD does not differentiate between different driving license classes and therefore does not include driving license classes with a minimum age of under 18 years.

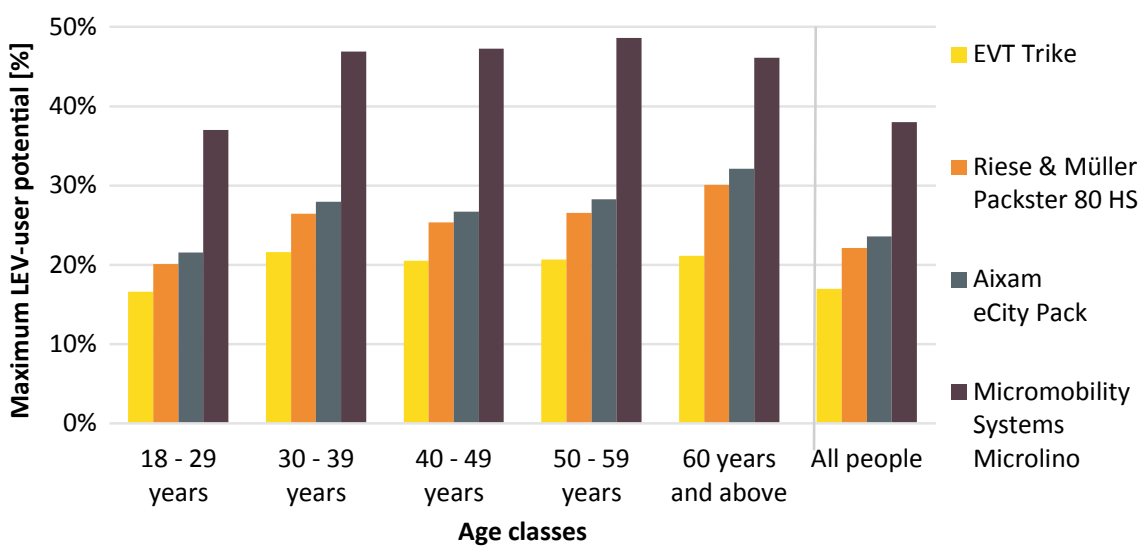

Fig. 3 Persons who could have used SEVs on the survey day, differentiated by different SEV models and age groups (maximum potential) 


\subsection{Feasible Transport Impacts and User Potentials of SEVs in Commercial Transport}

SEVs can be used for about 34-56\% of regular business-related trips, which are used as proxy for commercial transport (see Fig. 4). Due to the heterogeneity of commercial trips with a substantial amount of daily trip chains of $100 \mathrm{~km}$ or more; however, only about one tenth of the mileage could technically be replaced. The results for the KYBURZ DXP 4 are significantly lower in comparison with the other three SEV models. These findings represent an average; depending on the business sector, the percentages can be considerably higher, such as in postal delivery.

A further differentiation of the maximum substitutable trips was made with respect to the commercial trip purposes, such as business meetings, service trips, mobile nursery, or goods deliveries. This differentiation shows a relatively high degree of stratification for different dimensions of commercial transport (see Fig. 5). For the purpose of social service, healthcare, and nursery a maximum of $80 \%$ of the trips could be replaced by SEVs (in relation to the top-three SEV models that show a similar performance). For the purpose of customer service and business-related errands, a substitution level of $60 \%$ was found; similarly for visits, inspections, and meetings (substitution level some 50\%). Note that, the two previous groups of trip purposes might contain private companies as well as local authorities or municipal companies. The lowest maximum substitution rate of about $40 \%$ was found for transport, pick-up, and delivery of goods, which roughly corresponds to the courier, express, and parcel logistics services (CEP) industry but might also include more general types of delivery services. Looking at these results, SEVs seem to be more promising in business sectors where the transport of goods is

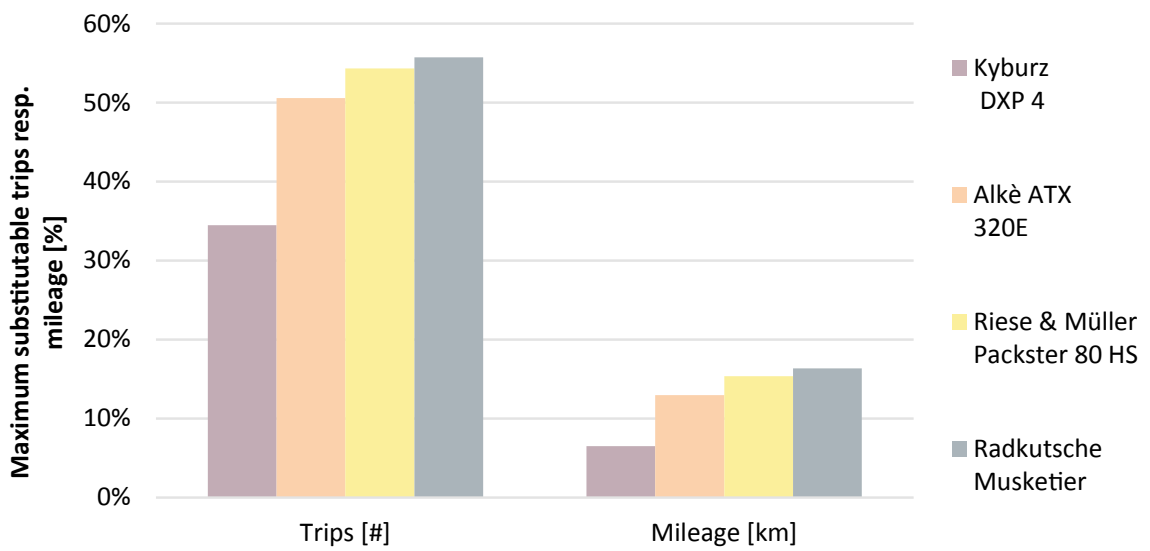

Fig. 4 Share of commercial transport trips and mileages on commercial trips that can be substituted by SEVs (maximum potential) 


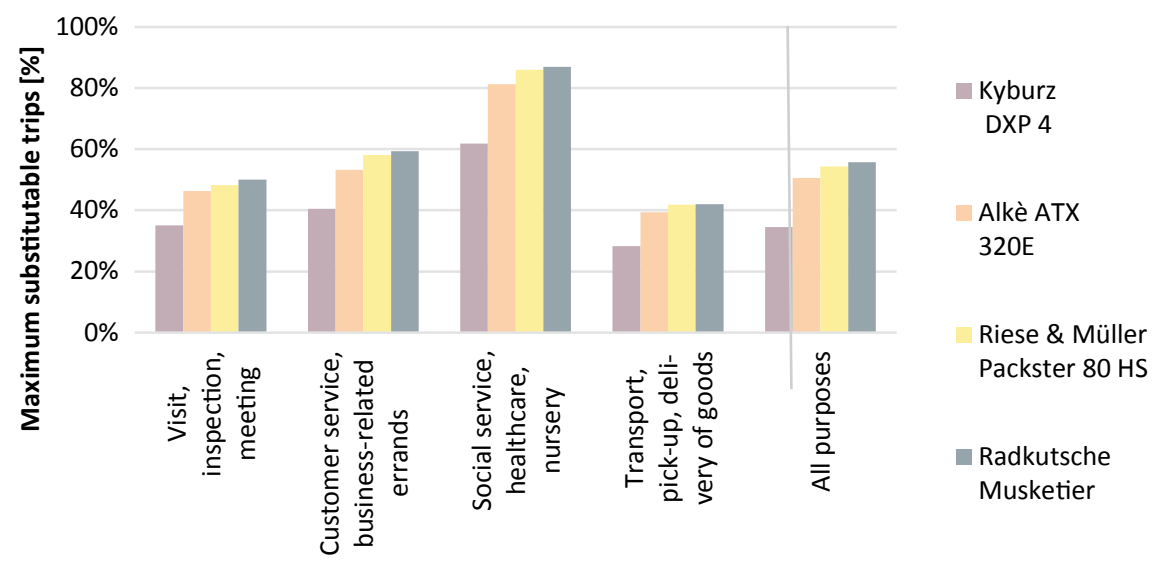

Fig. 5 Proportion of commercial transport trips that could be substituted by SEVs, differentiated by trip purposes (maximum potential)

not the core business but an additional requirement to fulfill the core business (e.g., any kind of mobile service).

Particularly in the case of freight transport, the limited data basis must be taken into account: If empirical data on actual payload requirements were available, the results would certainly lead to a further differentiation between the two differently-sized electric cargo bikes Musketeer (a heavy-load tricycle) and Packster (a "Long John" two-wheeler). Due to the vehicle design of the evaluated SEVs, only the SEV Alkè ATX is available for the transport of passengers, but due to the low general substitution potential, its use for this purpose is likely to be largely limited to locations such as airports or exhibition centers.

\subsection{Feasible Applications and Business Models of SEVS}

In passenger and commercial transport, there are various areas of application for SEVs, in line with the heterogeneous travel behavior of individuals and their private and professional activities. The interviewed experts see great opportunities in particular with regard to climate protection and the threat of driving bans for diesel and gasoline vehicles in city centers.

SEV Applications in Commercial Transport SEVs could be used commercially for CEP services, other delivery services, internal/on-site transports, and service trips.

Within CEP services, SEVs would rather be of implemented for courier deliveries, i.e., urgent $\mathrm{B} 2 \mathrm{~B}$ shipments delivered point-to-point by messengers. Technically, it is also conceivable to use them for the delivery of parcels to 
end-users (B2C). However, currently only a few of the available SEVs, such as the ALKE ATX, offer a sufficient carrying capacity. It is therefore less likely that SEVs will be used to a large degree in the parcel mass market, given the current regulation.

In contrast, SEVs could be used more frequently for other time-critical delivery services, especially for the delivery of prepared meals, as only a modest transport capacity is required here. Furthermore, SEVs could be used by retailers (or their contractors) for instant or time-window delivery options. However, due to low willingness-to-pay by customers, the feasibility of this business model might be a challenge.

SEVs are also suitable for internal or on-site commercial transports; this includes transport on larger company sites or residential facilities as well as transport between different sites of an organization or local authority. As these trips are often scheduled regularly with a homogeneous volume of goods, they can be adapted more easily to the limited ranges and loading capacities of SEVs.

Service trips are a heterogeneous group of trips within commercial transport in which the primary focus is not the transportation of goods, but the execution of services at the point of destination. These services require the transport of tools, spare parts, or other working materials. Some SEVs are well suited for service trips that only require moderate payloads and daily mileages, such as city cleaning and gardening, janitorial and facility services, technicians, craftsmen or nursing services.

SEV Applications in Passenger Transport In passenger transport, SEVs could be used for everyday mobility in the same way as other privately owned means of transport, such as the car. SEVs could, if the model characteristics allow it, be used on entire trip chains, e.g., from home to work, then to sport and back home in the evening. Particularly on shorter trip chains, SEVs are a comfortable transport solution independent of the present topography and often have weather protection. Many SEV models also offer the possibility of transporting goods, making them suitable for (smaller) shopping. Due to the lower land usage compared to the car, SEVs are also an interesting alternative means of transport in urban areas with limited parking space.

Another area of application is as mobility option for tourists. Especially in car-free tourism areas, e.g., nature parks, SEVs are an alternative to the bicycle or car for the mobility of tourists.

Moreover, SEVs could also be used in passenger transport on trip stages. This is feasible, for example, on the first or last mile of a public transport trip, i.e., on the stage between the public transport stop and the start or destination of the trip. In such an area of application, it would be conceivable that SEVs could be offered in sharing concepts. Similar to current bike-sharing concepts, parking facilities could be installed at public transport stops, so that a simple and quick transfer to and from public transport is guaranteed. 
Table 3 Sharing services with SEVs in Europe

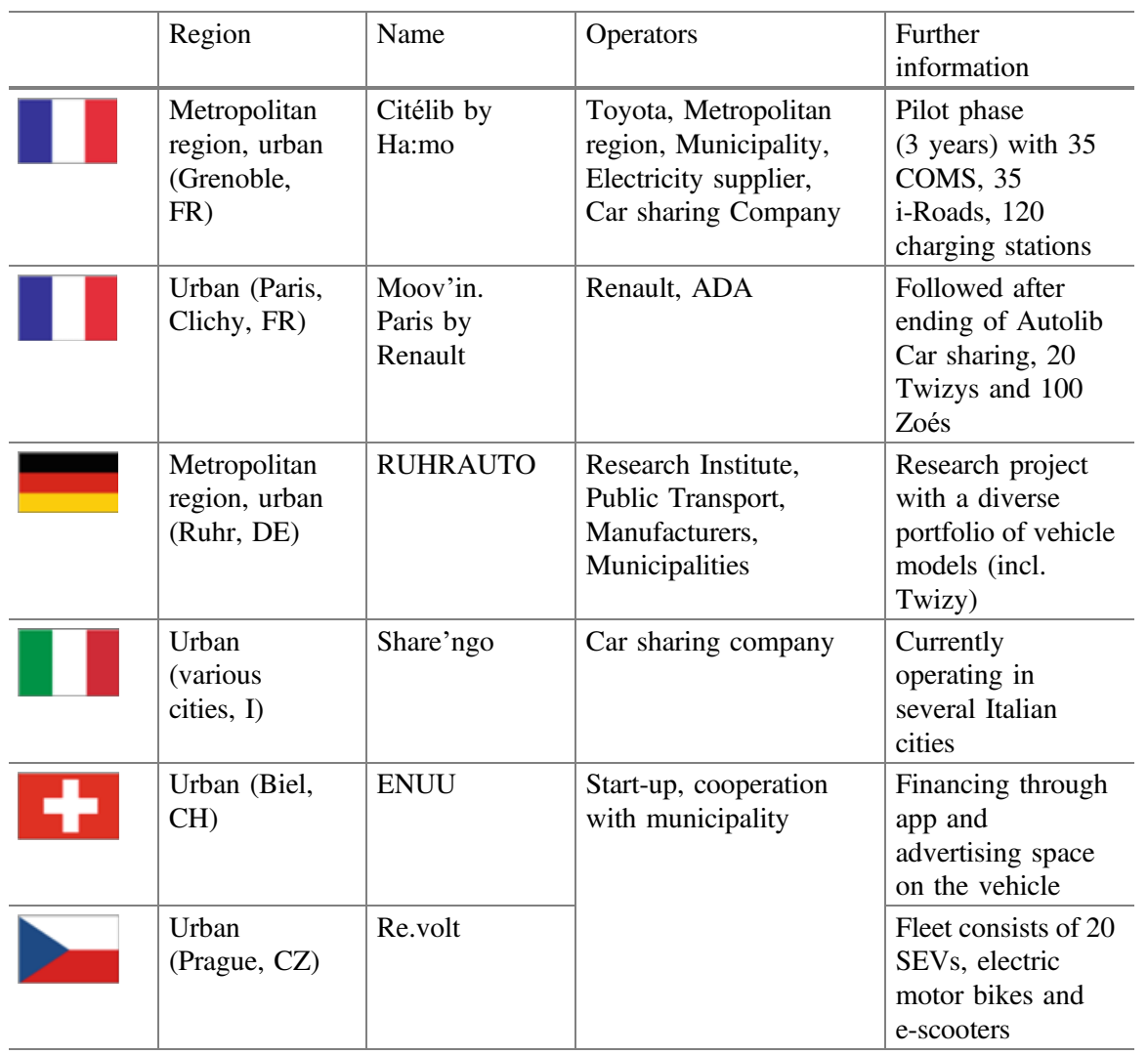

Business Models for Mobility Services A potential business model in passenger transport is the use of SEVs in shared fleets. Potential users can test and get to know SEVs without obligation. Such concepts are already in place in some European cities, see Table 3. The design of those sharing concepts varies. In some cases, SEVs are offered exclusively (e.g., Citélib by Ha:mo, Re.volt), in other cases further vehicle categories are available in addition to SEVs (e.g., cars and commercial vehicles). Users can thus choose between various vehicle categories depending on the purpose of the journey and their needs. This enables flexible mobility. Manufacturers acting as sharing providers often want to increase the use and awareness of their own vehicle models among the population. Other providers establishing and operating sharing fleets are municipalities, energy suppliers, public transport facilities, car sharing providers, or start-ups.

Sharing fleets with SEVs are at present still a niche market. Success on the demand side depends on various factors, for example, the attractiveness of the service, usage costs, local availability of the service, and ease of use. The creation 
of significant demand is fundamental to the development of financially successful business models. Furthermore, when selecting SEV models for sharing, it is important to ensure that they are robust in use and resistant to external damage, so that the maintenance and servicing costs remain manageable. The resale and residual value of SEVs from sharing fleets in the secondary market determine the success of the business model. Moreover, one sharing fleet operator pointed out in our interview that the requirements for the robustness and reliability of the vehicles when used in sharing fleets are higher than for private use. This should be taken into account when designing SEVs. At present, no conclusions can be drawn regarding the profitability of this business model. Sharing services offered by car manufacturers with fleets of cars are currently aimed primarily at offering their own mobility services, strengthening the bond with their own customer base, and thus reducing competition from other mobility-service providers [9]. Furthermore, the strong growth in subscribers is giving the impression of a strong growth in demand for sharing services.

\section{Conclusions and Outlook}

Our results show that, technically, SEVs could be used for $20-50 \%$ of private trips (depending on the SEV model and only counting trips that are parts of trip chains, if SEVs are suitable for the entire trip chain). This technical potential includes car trips, as well as trips on public transport or by bicycle and on foot. The potential is restricted by the criteria used for the analysis such as availability of weather protection and average speed on the longest trip of the trip chain. Extended future analysis could also analyze single trips in order to account for options such as car sharing and recharging during trip chains, thereby deriving an even higher potential. Within commercial transport, SEVs have been found to be particularly suitable for service-oriented activities such as healthcare, craftsmen, or municipal services. Concerning deliveries, time-critical point-to-point (courier) shipments or food deliveries seem to be more feasible than standard parcel deliveries.

If SEVs were to replace a significant share of the transport volumes of motorized passenger and commercial transport, they could contribute to climate protection. Due to the lower weight and lower speeds of SEVs compared to cars, less energy is required for their operation.

The presented analysis of the MiD was accompanied by expert interviews that included questions regarding any possible measures to foster SEVs. Many experts stated that, if a wider application of SEVs with the replacement of specific modes is desired, boundary conditions need to be actively shaped accordingly. Since SEVs have already been on the market for more than 12 years without gaining a high market share, significant shifts in transport modes seem unlikely unless parameters, such as regulation, taxes, boundary conditions of use, vehicle technology, variety of models or prices, change fundamentally. 
Future studies and real-world settings could evaluate how measures could foster SEVs as part of a sustainable transport system. According to the authors, measures should focus on areas of application, where public transport and active modes cannot offer attractive solutions, e.g., due to very low or disperse transport demand or to the physical constraints of users.

\section{References}

1. Honey, E., Lee, H., Suh, I.-S.: Future urban transportation technologies for sustainability with an emphasis on growing mega cities: a strategic proposal on introducing a new micro electric vehicle statement. WTR (3), 13 (2014). https://doi.org/10.7165/wtr2014.3.3.139

2. Santucci, M., Pieve, M., Pierini, M.: Electric L-category vehicles for smart urban mobility. Trans. Res. Part F Traffic Psychol Behav 14, 3651-3660 (2016)

3. Bauer, W., Wagner, S., Edel, F., Stegmüller, S., Nagl, E.: Mikromobilität. Nutzerbedarfe und Marktpotenziale im Personenverkehr. Stuttgart, Germany: Fraunhofer-Institut für Arbeitswirtschaft und Organisation IAO (2017)

4. International Energy Agency: Global EV Outlook 2019: Scaling-Up the Transition to Electric Mobility. OECD (2019)

5. ACEM: Motorcycle, Moped and Quadricycle Registrations in the European Union-20102018. (2019). Accessed 08 Mar 2019. [Online] Available: https://www.acem.eu/market-data

6. Ewert, A., Brost, M.K., Schmid, S.A.: Framework conditions and potential measures for small electric vehicles on a municipal level. WEVJ 11(1), 1 (2020). https://doi.org/10.3390/ wevj11010001

7. Nobis, C., Kuhnimhof, T.: Mobilität in Deutschland-MiD Ergebnisbericht. Study from infas, DLR, IVT and infas 360 on behalf of the German Ministry of Transport and Digital Infrastructure.

8. Brost, M., Ewert, A., Schmid, S., Eisenmann, C., Gruber, J., Klauenberg, J., Stieler, S.: Elektrische Klein- und Leichtfahrzeuge. Chancen und Potenziale für Baden-Württemberg on Behalf of E-mobil BW. Stuttgart, Germany (2019)

9. Zeit Online: Carsharing: BMW und Daimler stecken Milliardenbetrag in Mobilitätsfirma. ZEIT ONLINE, 22 Feb 2019. https://www.zeit.de/mobilitaet/2019-02/carsharing-bmwdaimler-investition-mobilitaetsfirma-elektroautos. Accessed 30 Apr 2019

Open Access This chapter is licensed under the terms of the Creative Commons Attribution 4.0 International License (http://creativecommons.org/licenses/by/4.0/), which permits use, sharing, adaptation, distribution and reproduction in any medium or format, as long as you give appropriate credit to the original author(s) and the source, provide a link to the Creative Commons license and indicate if changes were made.

The images or other third party material in this chapter are included in the chapter's Creative Commons license, unless indicated otherwise in a credit line to the material. If material is not included in the chapter's Creative Commons license and your intended use is not permitted by statutory regulation or exceeds the permitted use, you will need to obtain permission directly from the copyright holder. 